\title{
Desdobrando Tempos, Redescobrindo Olhares: Um Estudo de "Sinhazinha Na Janela" de Lula Cardoso Ayres
}

\author{
Unfolding times, rediscovering gazes: \\ a study of "Missy in the window" by Lula Cardoso Ayres \\ Maria Salete Borba* \\ *Universidade Estadual do Centro-Oeste, R. Frei Everaldo, 3499 - Centro, Chopinzinho - \\ PR, 85560-000, e-mail: nena.borba@gmail.com
}

RESUMO: O presente texto teve como objetivo fazer uma leitura da tela "Sinhazinha na janela" (s/d) do artista plástico pernambucano Lula Cardoso Ayres (1910-1987). A partir do repertório imagético formal-geométrico, próprio dos anos 1940 e 1950, em que a arte brasileira, e, mesmo a obra de Ayres, rumava ao concretismo, lemos o gesto como um elemento intrínseco à imagem. A fundamentação teórica é feita a partir do pensamento do filósofo italiano Giorgio Agamben, em especial, no texto "Notes sure le geste", de 1991, no qual o "gesto" é o principal motivo de suas reflexões.

PALAVRAS-CHAVE: Gesto; Lula Cardoso Ayres; Image/literatura.

ABSTRACT: The aim of this paper is to make a reading of "Missy in the window" (s/d) by pernambuco artist Lula Cardoso Ayres (1910-1987). From the formal-geometric imagery repertoire typical of the 1940s and 1950s, when the Brazilian art, and even the work of Ayres, was heading to concretism, we read the gesture as an intrinsic element in the image. The theoretical foundation is made from the thought of the Italian philosopher Giorgio Agamben, in particular the text "Notes sure le geste", 1991, in which the "gesture" is the main reason of his reflections.

KEYWORDS: Gesture; Lula Cardoso Ayres; Image/literature. 

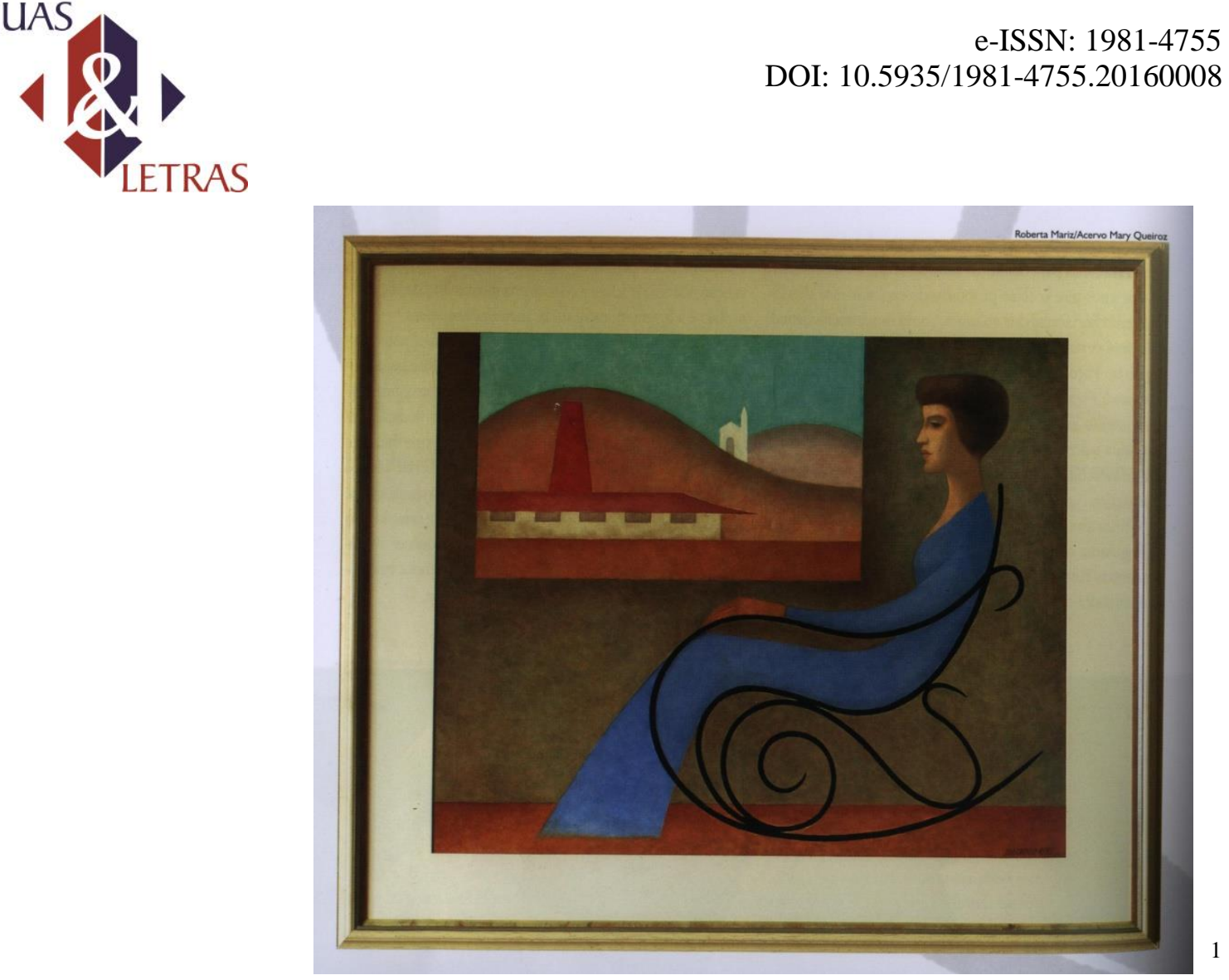

Le geste consiste à exhiber une médialité, à rendre visible un moyen comme tel. Du coup, l'être-dansun-milieu de l'homme devient apparent, et la dimension éthique lui est ouverte. Giorgio Agamben.

A professora e ensaísta Ana Luiza Andrade em seu ensaio chamado "Entre a espiral e o quadrado. Um quadrado de Lula Cardoso Ayres na moldura de obras de Gilberto Freyre e Osman Lins" de 2005, publicado pela revista Continente, faz uma leitura da obra de Lula Cardoso Ayres (1910-1987), "Sinhazinha na Janela" (s/d).

"Sinhazinha na Janela", não possui data, mas marca a trajetória do artista Lula Cardoso Ayres, que, assim como Cícero Dias (1907-2003), foi um dos amigos mais próximos do escritor Gilberto Freyre (1900-1987). A proximidade entre Ayres e Freire se deu por vários motivos desde a origem social, ambos vindos de famílias voltadas à produção do açúcar, até a amizade cultivada ao longo dos anos. O registro dessa amizade pode ser conferido nas ilustrações realizadas por Ayres para as diversas obras de Freyre; as ilustrações de Sobrados e mucanbos são um belo exemplo dessa parceria. Por sua vez, Gilberto Freire também teceu elogios não somente em textos escritos, mas ora em apresentações, ora em cartas de recomendações nas quais as qualidades do pintor eram salientadas.

\footnotetext{
${ }^{1}$ Lula Cardoso, "Sinhazinha na janela". Óleo sobre tela, s/ data. Acervo particular: Mary Queiroz.
} 


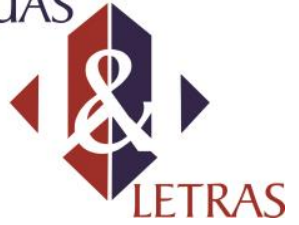

Ana Luiza Andrade partindo destas considerações vai além, destaca e sublinha as formas contrastantes da espiral e do quadrado como marcas de um modernismo meio barroco, existente na obra de Lula Cardoso Ayres, em especial em "Sinhazinha na Janela". Tais traços são para a professora vestígios e testemunhas das mudanças na própria sociedade, que estava em vias de se transformar de rural, em urbana.

Ao trazer à baila a obra Perfil de Euclydes e outros perfis, de Freyre, Ana Luiza Andrade nos apresenta o contraponto, o contraste entre o seco e o doce, o retilíneo e o orgânico existentes na cultura nordestina e que Gilberto Freyre recupera. Todas essas considerações vão se desenrolando, tal como, a espiral da cadeira da Sinhazinha passando por reflexões sobre Sobrados e mucambos, para salientar a diferença e a decadência de uma cultura ainda rural. É nesta leitura atenta, na descrição pontual que une e separa, ao mesmo tempo, a cidade e o campo, o geométrico e o orgânico, a espiral e o quadrado que Ana Luiza Andrade nos apresenta o artista Lula Cardoso Ayre e sua personagem lânguida, etérea e fantasmática.

\begin{abstract}
Aí um narrador-pintor também penetra o interior da casa onde está a mulher sentada, desvirginando seu íntimo ao romper o seu segredo de antiga guardiã. Fantasmático, o corpo se cola ao fino contorno da cadeira, desvanescente, residual. Sua infertilidade é substituída pelas montanhas férteis, redondas com a proliferação das canas a engordar as terras de massapé, cuja disseminação, pelo bueiro fálico da usina, centro de produção, coincide com o ponto alto da paisagem vista pela janela: 'o gordo, o farto, o satisfeito, o mole das formas; seios macios como que de carne; o pegajento da terra; a doçura do massapê' (Freyre, Perfil de Euclydes). Independente da prole do senhor, a usina, sendo agora o centro da casa antiga, desloca a mulher para o sobrado urbano. Embora a oscilação de seus pensamentos possa indicar o contrário, esta figura, substituída, será fantasma do passado que se dobra ao presente capitalista, sem que haja sensível alteração no quadro, do campo (em Lula) para a cidade (em Osman). (ANDRADE, 2005, p. 56).
\end{abstract}

É essa mulher fantasma "que se dobra ao presente capitalista", que aparece em primeiro plano na tela de Lula Cardoso Ayres, e que é o estopim para a análise sobre o gesto. $\mathrm{O}$ gesto não será lido como um elemento a mais, ou algo que advém e está intrínseco à história da pintura, mas como algo que ultrapassa a história tradicional da pintura, que se revela nos elementos de composição da tela e desdobra-se na história cultural.

Portanto, o gesto em Lula Cardoso é uma construção. Ora funciona como elemento que ganha destaque a partir de seu caráter memorativo, ativador de uma memória intrínseca às formas e aos objetos. Esse caráter memorativo pode ser lido na 
forma espiralada da cadeira de balanço que contrasta com as formas geométricas que enquadram tanto, a cena industrial, quanto a própria mulher. Ora, o gesto do qual tratamos se desdobra num ir e vir de reflexões, que nos possibilita elencar tempos díspares, que se unem no quadro apontando transformações sociais que tocaram a sociedade: aquele das fazendas, do interior privado, contrastando com o tempo do abandono do campo pela vida na cidade, um tempo acelerado, onde o interior privado torna-se público.

Ao adentrar-se o interior da casa da sinhazinha o que se verifica é o registro da transformação industrial enquadrado na parede como uma sorte de janela, e, ao mesmo tempo, da perda do fazer manual, orgânico próprio da cultura agrícola do final do século XIX e início do século XX. Pensar nessa cultura dos gestos orgânicos que passa a ser esquecida com a transformação das tecnologias, trago à baila o filósofo italiano Giorgio Agamben.

Agamben no texto "Notes sur le geste", cuja primeira edição é de 1991, faz uma análise sobre o gesto a partir de investigações científicas em torno do movimento humano, mais especificamente, da caminhada. Em suas considerações sobre o gesto, Agamben retorna, num primeiro momento, ao século XIX, em especial, às pesquisas sobre a caminhada, de Gilles de la Tourette realizadas em 1886 cujo título: Études cliniques et physiologiques sur la marche, foi um dos primeiros estudos científicos realizados sobre "um dos gestos mais ordinários do ser humano", tal como afirma Agamben. Por outro lado, o filósofo italiano também traz à tona outro estudo, agora, de Balzac: Théorie de la démarche, realizado cinquenta anos antes do estudo de De La Tourette. A diferença entre os dois estudos, segundo Agamben, está no fato de que em Gilles de la Tourette, há uma aproximação com o cinema. “Ce qui n'était aux yeux de Balzac que l'expression d'un caractère moral est désormais soumis à un regard qui annonce déjà le cinématographe: '[...]'.” (AGAMBEN, 1991, p.31). Agamben dá continuidade ao seu texto comentando as experiências, os estudos sobre as impressões das pegadas dos pacientes realizados por Gilles de la Tourette, e, como essas reproduções impressas lembravam as séries de instantâneos realizadas por Muybridge na Universidade da Pensilvânia na mesma época. Ainda sobre os estudos de Gilles de la Tourette, o filósofo italiano vai sublinhar que no ano seguinte aos estudos sobre a caminhada, o mesmo estudioso publica um estudo sobre descoordenção motora que resultou de suas investigações de quadros clínicos; esses ficaram conhecidos como sídrome de Gilles de la Tourette. 
La même mise à distance du geste le plus quotidien par laquelle la méthode des empreintes était devenue possible est ici appliquée à la description d'une impressionnante prolifération de tics, de spasmes, de saccades et de maniérismes qui ne peut être définie que comme une catastrophe généralisée de la sphère de la gestualité. Le patient n'est plus en mesure de commencer ni de mener à terme les gestes les plus simples; à peine esquissé, le mouvement est interrompu et disloqué par des secousses incohérentes et par des tremblements où la musculature paraît danser (chorée) sans aucune finalité motrice. (AGAMBEN, 1991, p.32).

No entanto, Giorgio Agamben observa ainda que tal disfunção, ou melhor, transfiguração dos gestos passa a ser esquecida até 1971, quando Oliver Sacks, passeando em Nova Iorque, afirma ter visto três casos da síndrome de Gilles de la Tourette na rua num curto espaço de tempo. Agamben, conclui essa primeira parte, afirmando que a ataxia, a distonia e os tiques, que haviam sido consideradas doença num determinado período, por um bom tempo passaram a ser consideradas dentro da norma numa outra época. Esse é o percurso inicial do texto que se divide em cinco partes dedicadas ao estudo do gesto.

O estudo de Agamben ao analisar o procedimento da perda dos gestos pela sociedade ocidental, e a tentativa de recuperá-los em outros momentos da história pela via do cinema, ajuda-nos a ler o gesto no quadro do pintor pernambucano como um dispositivo que agencia elementos que vão além da tela. Em Lula Cardoso Ayres a tela em si é mais uma tentativa de, no seu deslocamento, recuperar as perdas de uma época. Como o instantâneo de Muybridge, a tela faz parte de um conjunto que funciona pelo contato, pelo agenciamento de ações.

Na segunda parte do seu estudo sobre o gesto, Agamben demonstra como a mesma sociedade burguesa que a partir do século XIX foi perdendo os seus gestos, tenta recuperá-lo por uma via introspectiva, voltada para a psicologia. Para tanto traz à tona, os estudos de Nietzsche que ficam entre os dois pólos: a perda e a transfiguração do gesto. É a mesma indecibilidade lida em Nietzsche por Agamben que lemos na figura lânguida da sinhazinha que nos é apresentada em azul celeste. O corpo sinuoso da sinhazinha acompanhando o desenho solto e espiralado da cadeira de balanço que simula um movimento mecânico de ir e vir, de se comunicar com o passado e com o presente, com o interior e o exterior, com o urbano e com o rural.

É essa cadeira que segura e balança a sinhazinha, que passa a ser o elemento que interrompe a narrativa. As linhas soltas e delgadas da cadeira nos fazem ver as linhas retas que formam a paisagem do quadro cuja composição é quase que totalmente, 


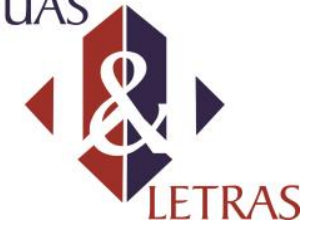

geométrica. Além disso, nos leva a pensar na produção artística de Lula Cardoso Ayres que se dedicou tanto à representação, quanto à vertente mais concreta da pintura.

"Sinhazinha na janela" está no limiar dessas duas linguagens artísticas.

Ou seja, é o mesmo olhar que captura, no início do século XX, as modificações ocorridas na sociedade devido à industrialização, que registra com cores e formas geométricas o surgimento de uma sociedade maquínica. Ou melhor, o mesmo traço que captura e transforma a paisagem em linhas retas, duras, ângulos e formas geométricas nos faz ouvir o som das máquinas e o cheiro da fumaça das chaminés. Assim sendo, a presente leitura do quadro de Ayres concorda com Agamben quando nos diz que o eterno retorno de Nietzsche é um gesto no qual "a potência e o ato, o natural e a maneira, o contingente e a necessidade são indissociáveis".

Outro teórico importante, Aby Warburg, não é deixado de lado por Giorgio Agamben. Agamben chama a atenção para os estudos sobre as imagens feito por Warburg, que foram reunidos em seu atlas chamado Mnemosyne. Mnemosyne, continua Agamben, oferece uma representação virtual do movimento dos gestos na sociedade ocidental: da Grécia ao fascismo.

En fait, Warburg a transformé l'image (dont Jung fera encore le modèle de la sphère méta-historique des archétypes) en un élément résolument historique et dynamique. À cet égard, Mnemosyne, l'atlas aux mille photographies qu'il devait laisser inachevé, loin de n'être qu'un immobile répertoire d'images, offre une représentation à mouvement virtuel des gestes de l'humanité occidentale, de la Grèce classique jusqu'au fascisme (c'est-à-dire quelque chose qui s'apparente davantage à De Jorio qu'à Panofsky); [...]. (AGAMBEN, 1991, p.33).

É pensando a imagem a partir das suas relações com a história da humanidade que Agamben dá continuidade ao texto, e, no terceiro tópico apresenta e propõe ampliar o conceito deuleuziano conhecido como imagem-movimento:

Il faut prolonger l'analyse deleuzienne et montrer qu'elle concerne, de façon générale, le statut de l'image dans la modernité. Or, cela signifie que la rigidité mythique de l'image s'est ici vue disloquée, et qu'à proprement parler ce n'est pas d'images qu'il devrait être question, mais de gestes. De fait, toute image est animée d'une polarité antinomique: elle est d'une part réification et annulation d'un geste (il s'agit alors de l'imago comme masque de cire mortuaire ou comme symbole), dont elle conserve d'autre part la dynamis intacte (ainsi dans les instantanés de Muybridge ou dans n'importe quelle photographie sportive). Le premier pôle correspond au souvenir dont s'empare la mémoire volontaire; le second, à l'image qui jaillit comme un éclair dans l'épiphanie de la mémoire involontaire. Et 


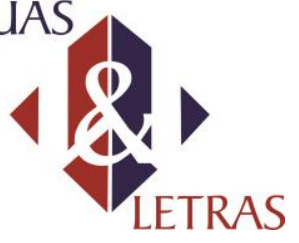

tandis que la première vit dans un isolement magique, la seconde renvoie toujours au-delà d'elle-même, vers un tout dont elle fait partie. Même la Joconde, même les Ménines peuvent être envisagées non pas comme des formes immobiles et éternelles, mais comme des fragments d'un geste ou comme des photogrammes d'un film perdu, qui seul pourrait leur restituer leur véritable sens. Car toujours, en toute image, est à l'œuvre une sorte de ligatio, un pouvoir paralysant qu'il faut exorciser; et c'est comme si de toute l'histoire de l'art s'élevait un appel muet à rendre l'image à la liberté du geste. (AGAMBEN, 1991, p. 34).

Esse gesto reinventado que está nas imagens, que atravessa a reflexão de Giogio Agamben nos possibilita ler "Sinhazinha na janela", uma pintura que está no limiar da linguagem formal-geométrica, como um dispositivo que integra através de suas diagonais e planos a memória, a experiência de uma época que são representadas pela figura da sinhá em sua cadeira de balanço com a qual o artista mais que demonstrar uma sociedade padronizando-se, tornando-se assim, tecnológica, ou melhor, maquínica, traz ainda os resquícios de um passado, os vestígios que ganham destaque na própria figura da sinhá.

Ainda pode ser dito que a tecnologia que nos é apresentada é também aquela que instaura a apatia moderna: a sinhazinha em azul celeste, etéreo, não assinala o êxtase do progresso, mas a suspensão. O gesto, nesse caso, é tanto um ato que gira em torno das mudanças que atingem o coletivo, quanto um mecanismo maquínico individual resultado de movimentos repetitivos, como os da cadeira de balanço.

A cena retratada por Lula Cardoso é, de certo modo, um desses cortes que nos possibilitam ler o moderno como algo em construção, em que sempre se está à espera de algo novo. É essa espera individual e coletiva como gesto, como atitude e potência de um corpo social e individual. Esses aspectos aproximam e afastam a "Sinhazinha na Janela" de Lula Cardoso de tempos remotos, e, nesse vai e vem a aproxima do anjo de Paul Klee. 

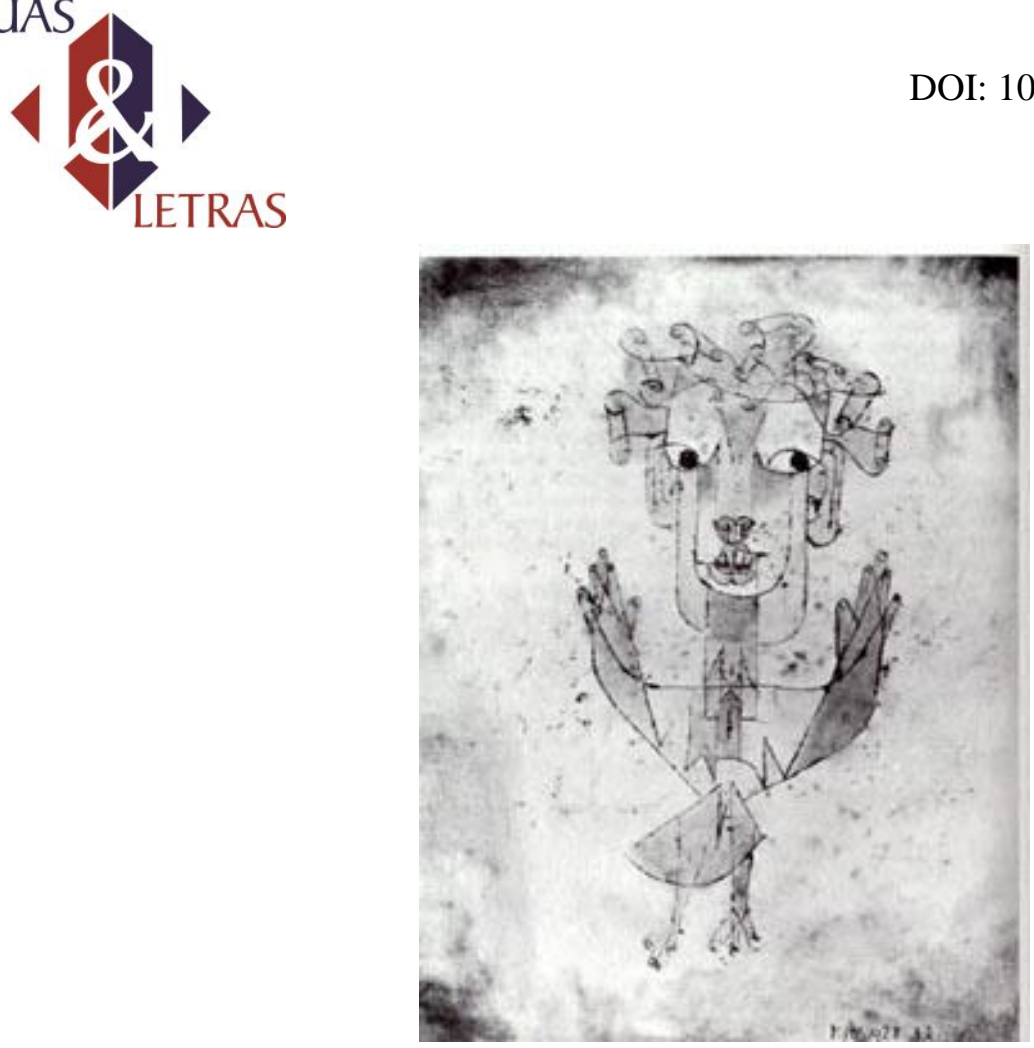

Figura 1-Paul Klee. “Angelus Novus”, 1932.

Angelus Novus é o anjo que ilustra a tese 9 do ensaio "Sobre os conceitos da história"(1940), de Walter Benjamin. O filósofo alemão nos diz que o anjo de Klee parece se afastar de algo que ele encara fixamente: a catástrofe. O passado enquanto catástrofe, continua Benjamin, é o que o anjo da história vê.

Há um quadro de Klee que se chama Angelus Novus. Representa um anjo que parece querer afastar-se de algo que ele encara fixamente. Seus olhos estão escancarados, sua boca dilatada, suas asas abertas. $\mathrm{O}$ anjo da História deve ter esse aspecto. Seu rosto está dirigido para o passado. Onde nós vemos uma cadeia de acontecimentos, ele vê uma catástrofe única, que acumula incansavelmente ruína sobre ruína e as dispersa a nossos pés. Ele gostaria de deter-se em suas asas com tanta força que ele não pode mais fechá-las. Essa tempestade o impele irresistivelmente para o futuro, ao qual ele vira as costas, enquanto o amontoado de ruínas cresce até o céu. Essa tempestade é o que chamamos progresso. (BENJAMIN, 1994, p. 226).

Se prestarmos atenção nas palavras de Walter Benjamin, constataremos que o anjo de Klee representa a história construída de ruínas; e essas ruínas são imagens que constituem o presente. O presente é o que o impele para o futuro. Assim como o anjo de Klee, a sinhazinha etérea de Ayres em sua cadeira de balanço se desdobra entre dois tempos, está nesse limiar temporal, seu olhar em diagonal aguarda o futuro apaticamente, como algo inevitável. Já não é o medo que é revelado, mas a falta de desejo, de reação: a apatia.

Considerando as palavras de Benjamin, é necessário manter certo distanciamento para se olhar para o presente. Tal atitude requer uma postura "celestial", 


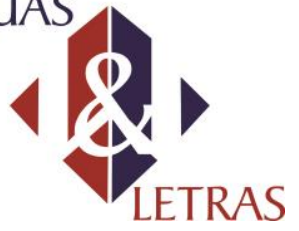

pois, o presente que é constituído de ruínas advindas do passado, de imagens fragmentadas, de espaços, de intervalos que requerem um olhar atento. $\mathrm{O}$ que nos sugere olhar para o presente como se olha para o passado, observando o que está entre os fatos, entre as imagens. É mais ou menos isso que nos sugere o anjo de Klee: distanciamento e pausa, pois, não sendo nem homem nem Deus, ele está numa posição ímpar, demonstrando que ao mesmo que possui características imortais, possui outras características que o aproximam do homem: a aparência. Porém, não é nem homem nem Deus, estando entre os dois planos, o terreno e o celestial, o humano e o divino, entre o ser e as coisas.

Já a sinhazinha em azul celeste e de olhar lânguido, parece estar hipnotizada pelas mudanças, e, em seu movimento, fica em suspensão na espiral da sua cadeira e, também, do tempo. E desse modo, a sinhazinha fantasmática une os tempos que ela observa de sua cadeira que, devido seu balanço rememorativo, a captura, ao suspendêla.

\section{REFERÊNCIAS}

AGAMBEN, Giorgio. Notes sur le geste. Disponível em: $<$ http://lemagazine.jeudepaume.org/2013/04/giorgio-agamben-notes-sur-le-geste/> Acesso em: 27 abril 2015.

. Notes sur le geste. Trafic. No.1, Hiver, 1991.

ANDRADE, Ana Luiza. "Entre a espiral e o quadrado. Um quadro de Lula Cardoso Ayres na moldura de obras de Gilberto Freyre e Osman Lins". In: Revista Continente Multicultural. Ano V, n.58- Outubro/2005.

BENJAMIN, Walter. O que é o teatro épico? Um estudo sobre Brecht. In: Magia e técnica, arte e política: ensaios sobre literatura e história da cultura. Tradução de Sérgio Paulo Rouanet. Prefácio de Jeanne Marie Gagnebin. 7ª ed. São Paulo: Brasiliense, 1994. (Obras escolhidas. V.I).

Sobre os conceitos da história. In: Magia e técnica, arte e política: ensaios sobre literatura e história da cultura. Tradução de Sérgio Paulo Rouanet. Prefácio de Jeanne Marie Gagnebin. 7ª ed. São Paulo: Brasiliense, 1994. (Obras escolhidas. V.I). DELEUZE, Gilles. "Cinema, corpo e cérebro, pensamento". A imagem-tempo. Cinema II. Tradução de Eloísa de Araujo Ribeiro. São Paulo: Brasiliense, 2005.

Data de recebimento: 02/05/2015

Data de aprovação: 28/11/2016 